\title{
Esophageal motility disorders: new perspectives from high-resolution manometry and histopathology
}

\author{
Hiroki Sato $^{1}$ (D) Kazuya Takahashi $^{1} \cdot$ Ken-ichi Mizuno $^{1} \cdot$ Satoru Hashimoto $^{1} \cdot$ \\ Junji Yokoyama $^{1} \cdot$ Go Hasegawa $^{2} \cdot$ Shuji Terai $^{1}$
}

Received: 19 July 2017/ Accepted: 9 November 2017/Published online: 13 November 2017

(C) Japanese Society of Gastroenterology 2017

\begin{abstract}
High-resolution manometry (HRM) and peroral endoscopic myotomy (POEM) have contributed significantly to the field of esophageal motility disorders in recent years. The development of HRM has categorized various esophageal motility disorders with a focus on a diverse range of manometric anomalies. Additionally, the Chicago classification criteria is widely used for manometric diagnosis. Moreover, POEM was introduced as a minimally invasive radical therapy for achalasia and shows promise for other spastic esophageal motility disorders as well. POEM has also enabled a transluminal endoscopic approach for determining the histology of the esophageal muscle layer, which is expected to assist in elucidating the etiology of disorders associated with esophageal motility. The purpose of this review is to update the diagnosis, pathology, and treatment of esophageal motility disorders, with a focus on the recent advances in this field.
\end{abstract}

Keywords Achalasia - Peroral endoscopic myotomy · High-resolution manometry · Chicago classification · Jackhammer esophagus

Hiroki Sato

pyloki@yahoo.co.jp

1 Division of Gastroenterology and Hepatology, Niigata University Medical and Dental Hospital, 757-1, Asahimachidori, Chuo-ku, Niigata, Niigata 951-8510, Japan

2 Division of Cellular and Molecular Pathology, Department of Cellular Function, Niigata University Graduate School of Medical and Dental Sciences, Niigata, Japan

\section{Introduction}

Achalasia is a well-known primary esophageal motility disorder. The disease concept was first described more than 300 years ago as a food blockage in the esophagus [1]. In 1927, the Greek term "achalasia” was first used by Hurst, and characterized as a "failure of relaxation" of the lower esophageal sphincter (LES) after swallowing [2]. With the advent of esophagography and endoscopy, the old symptom-based disease concept could be characterized more objectively, such as observing aperistalsis, esophageal dilation, poor emptying of barium in the esophageal body, minimal LES opening, and a "bird-beak" appearance through radiography, and endoscopically by confirming a dilated esophagus with retained saliva, liquid, and undigested food in the absence of a mucosal fibrotic stricture or tumor [3]. The appearance of rosette-like esophageal folds, or a pinstripe pattern are characteristic endoscopic findings in achalasia $[4,5]$. Moreover, conventional manometry was developed, and it defined a manometric pattern of achalasia as insufficient relaxation of the LES, and loss of esophageal peristalsis. Although the clinical diagnosis and treatment of achalasia have been systematized, its pathophysiology and etiology are yet unknown [6-10].

In conventional manometry, a 'dent sleeve sensor' was necessary for the precise evaluation of LES function. This is because a pseudo-relaxation of the LES due to postdeglutitive esophageal shortening cannot be ruled out with conventional manometry. A dent sleeve sensor is $6 \mathrm{~cm}$ in length and allows the LES to move relative to it without a loss of recorder contact $[11,12]$. One drawback is that an infused catheter system is applied to it (Fig. 1a), making the preparation and procedure of the manometry examination complicated. Additionally, the catheter is connected to large equipment used for analyzing the change of water 


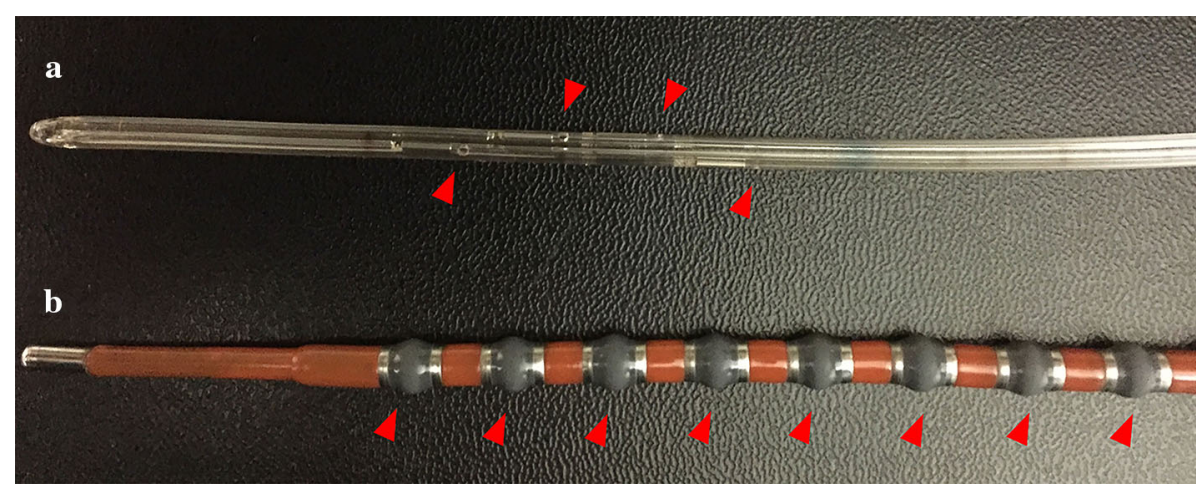

Fig. 1 a Infused catheter of conventional manometry (Dentsleeve Ltd, Ontario, Canada); a small stream of distilled water passes through a spiral-arranged side hole (red triangle) in the catheter sensor. The catheter sensor measures the motion of the gastrointestinal tract as it blocks this water flow; this is the intra-esophageal pressure. b A solid-state catheter of high-resolution manometry

flow and numerically quantifying it, thereby preventing easy bedside use [13]. The development of high-resolution manometry (HRM) was started in the 1990s with Clouse's studies [14, 15], and then applied in 2000 in a clinical setting [16]. HRM has closely-spaced pressure sensors, usually $1-1.5 \mathrm{~cm}$ apart, with $20-36$ circumferential channels per catheter (Fig. 1b), and utilizes a water infused catheter as well as a transducer catheter [17]. In a HRM transducer catheter, each pressure sensor directly senses changes in intraluminal pressure, and transforms it into an electrical signal. The development of an 'e-sleeve' application in HRM (Fig. 2) provides the maximum pressure over a 6-cm distance, similar to the dent sleeve sensor in conventional manometry, and allows for better characterization of LES pressurization and relaxation. Pressure topography plotting in HRM enables visualization of deglutitive esophageal function, and it allows for more rapid positioning of the catheter array. HRM can better define the manometric variation of esophageal motility disorders [18-20]. In 2012, the Chicago classification (CC) was developed and used as the HRM-based standardized criteria of esophageal motility disorders [21]. More recently, the v3.0 was published with further revisions [22].

In 2007, submucosal endoscopic esophageal myotomy was described [23], and peroral endoscopic myotomy (POEM) was reported in 2010 as a new minimally invasive endoscopic treatment for achalasia (Fig. 3a) [24]. We subsequently introduced endoscopic muscle layer biopsy during POEM (peroral esophageal muscle biopsy [POEMb]) to investigate the histology (Fig. 3b) [25]. This review is to update the diagnosis, pathology, and treatment of esophageal motility disorders, with a focus on the recent advances in this field (Fig. 4).
(Starlet, Starmedical Ltd, Tokyo, Japan); closely spaced circumferential pressure sensors (red triangle), $1 \mathrm{~cm}$ apart with 36 circumferential channels per catheter, each directly senses changes in intraluminal pressure, and transforms it into an electrical signal (transducer method)

\section{High-resolution manometry}

The display of HRM (Fig. 2) depicts esophageal pressure activity from the pharynx to the stomach (longitudinal axis), and from swallowing to the post-deglutitive period (horizontal axis). To assess deglutitive LES relaxation, integrated relaxation pressure (IRP) is used as a parameter. The loss of LES relaxation is the most important element for the diagnosis of achalasia. The IRP is measured after deglutitive upper sphincter relaxation from the anticipation of esophago-gastric junction (EGJ) relaxation until peristaltic wave arrival. An e-sleeve measurement is taken within $10 \mathrm{~s}$ and the $4 \mathrm{~s}$ during which the e-sleeve value is least determined. The next parameter is distal latency (DL), which has an important role for the assessment of the esophageal contraction pattern. DL is the interval from upper esophageal sphincter relaxation to the contractile deceleration point (CDP); a value less than $4.5 \mathrm{~s}$ defines a premature contraction. In non-symptomatic controls, it takes more than $4.5 \mathrm{~s}$ for a peristaltic wave to reach the CDP. The CDP is the inflexion point in the contractile front propagation velocity in the distal esophagus. The distal contractile integral (DCI) is also another indicator of the contraction pattern, particularly for the assessment of peristaltic strength. If hypercontractility involves the LES area, it was suggested to incorporate the LES into the DCI measurement domain.

At present, several catheter types and accompanying computer systems are available for HRM; thus, the different parameter cut off values between these products should be interpreted appropriately [26]. For example, an IRP $>15 \mathrm{mmHg}$ for achalasia diagnosis should only be used for the Medtronic system. Patient positioning for the procedure as sitting vs supine is also a concern [27]. 

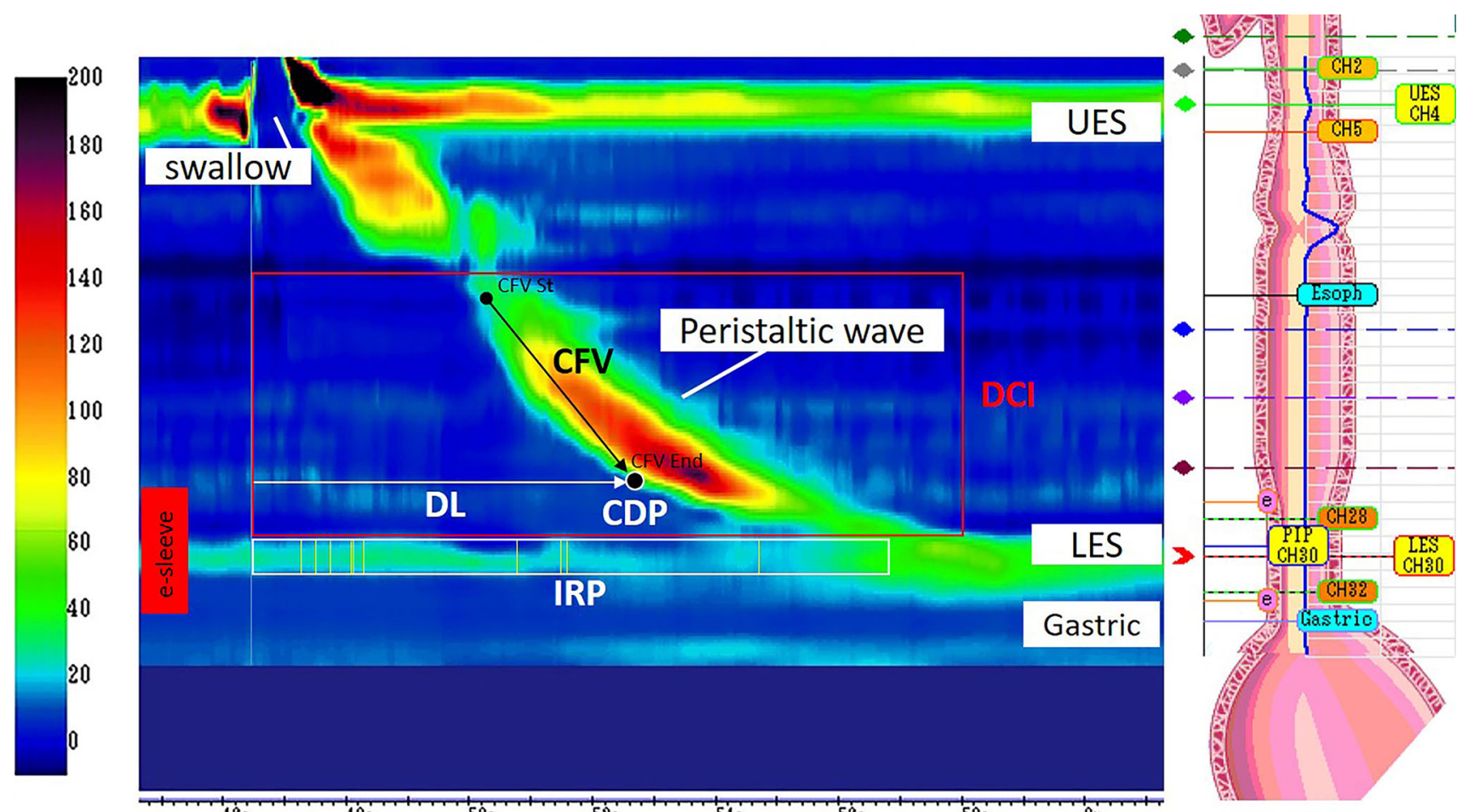

Fig. 2 The normal swallow and peristaltic wave observed on highresolution manometry. Synchronized with upper esophageal sphincter (UES) opening during liquid swallowing, lower esophageal sphincter (LES) relaxation is seen in the level of the e-sleeve. The peristaltic wave propagates gradually, from UES to LES. Time is on the $x$ axis

\section{Achalasia}

\section{Subtypes of achalasia on HRM}

The CC defines achalasia as insufficient relaxation of the LES (IRP > upper limit of normal) and no normal peristalsis. Based on this classification, achalasia is categorized into the following three subtypes: type I (classic achalasia), mean IRP > upper limit of normal (a common finding in all achalasia subtypes), and $100 \%$ failed peristalsis; type II, no normal peristalsis, and pan-esophageal pressurization with $\geq 20 \%$ of swallows; type III, no normal peristalsis, and preserved fragments of distal peristalsis or premature (spastic) contractions with $\geq 20 \%$ of swallows (Fig. 5).

\section{Histopathology of achalasia}

Previously, histological examination via Heller's myotomy [28], surgical esophageal resection, or autopsy revealed the common findings of degeneration of the Auerbach plexus or interstitial cells of cajal (ICCs), and fibrotic tissue replacement in the esophageal muscle layer in achalasia [29-34]. Inflammation was also observed, although there was some variation regarding the inflammatory cell type (mostly lymphocytes and, to a lesser extent, eosinophils). and distance from the nares is on the $y$ axis. UES upper esophageal sphincter, $E S$ lower esophageal sphincter, $C F V$ contractile front velocity, $D L$ distal latency, $C D P$ contractile deceleration point, IRP integrated relaxation pressure, $D C I$ distal contractile integral

Moreover, the infiltrate was patchy; therefore, specimen infiltration was related to sample size [34-36]. Although the manometric subtype of these reports was unknown, most of these reports likely showed histological findings of type I (classic) achalasia because of the sampling bias seen with surgical cases of long disease duration or those with severe symptoms. Recently, Sodikoff et al. retrospectively analyzed the conventional manometry pattern in patients with achalasia according to the CC and compared it with surgical specimens. They reported a greater degree, but similar pattern of ganglion cell loss observed in type I compared to that in type II, and suggested the pathology that type I achalasia represents a progression from type II achalasia [37]. We prospectively collected data of HRM and compared with the findings from muscle layer specimens obtained via a novel endoscopic technique, POEM-b, as described before. Our study showed that type I and II achalasia had a similarly reduced number of ICCs compared to a preserved number in type III, and severe fibrosis was only observed in type I (Fig. 3c-e) [38]. Although the correlation between the manometric subtypes and histopathology in achalasia has yet to be clarified, Kahrilas and Boeckxstaens reported that type III achalasia is likely a postganglionic nerve disorder with preservation or even augmentation of vagal extrinsic cholinergic modulation 

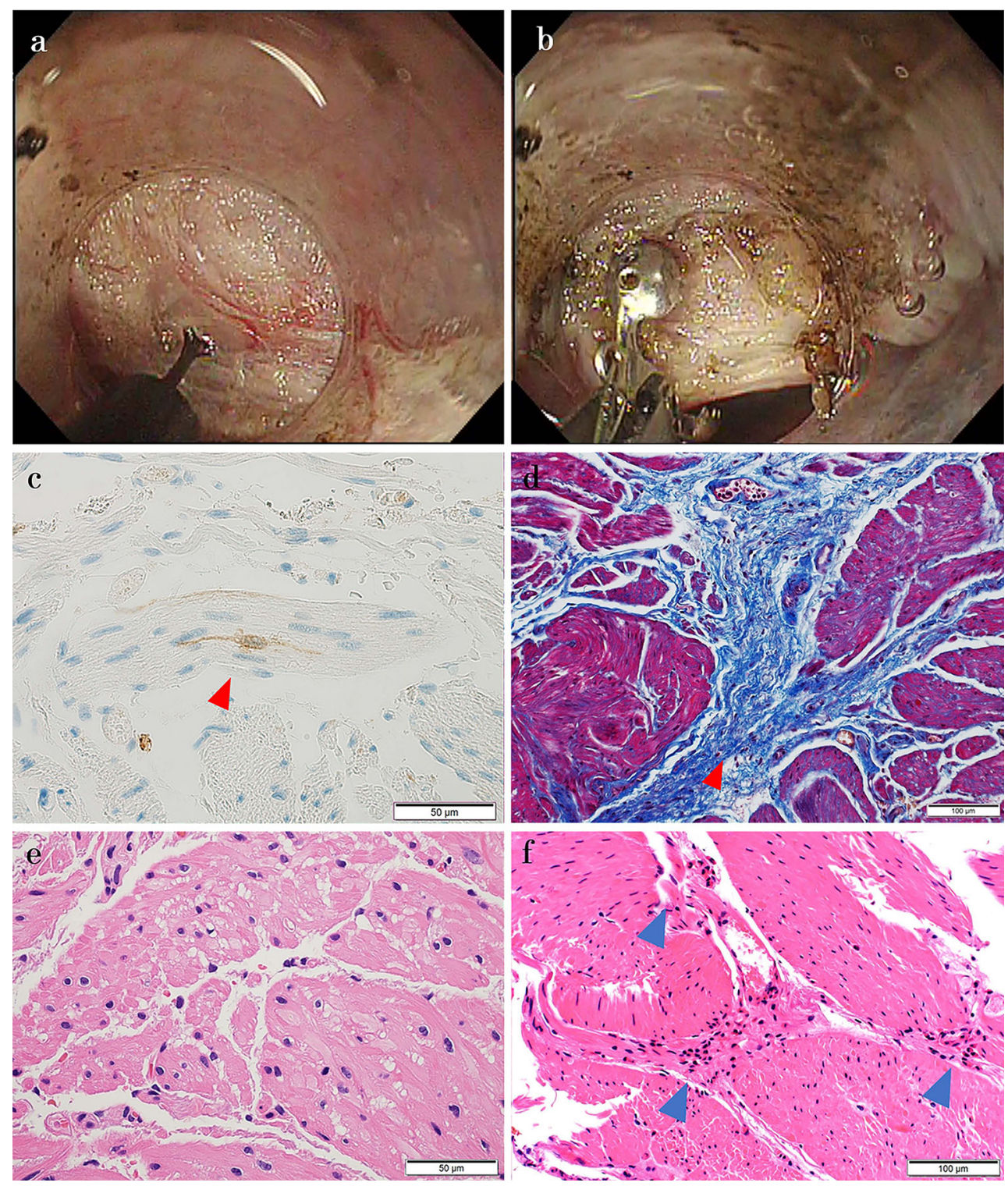

Fig. 3 a Peroral endoscopic myotomy (POEM): myotomy of the circular esophageal and gastric muscle bundles is performed under direct vision. b POEM-b: during POEM, full-thickness esophageal muscle layer biopsies can be performed using both ends of biopsy forceps. c Immunohistochemical staining for c-kit (CD117) of the esophageal muscle layer sample in a patient with achalasia. The number of spindle-shaped interstitial cells of cajal (red triangle) is

reduced. d Fibrosis (red triangle) is expanding in intersmooth muscle bundles in achalasia. Ganglion cells are rarely observed. e Vacuolization of the myocyte cytoplasm in the muscularis propria is observed in advanced cases of achalasia, which reportedly may be a degenerative change related to ischemia [34]. f Eosinophilic infiltration in the perivascular and perimysial areas in some cases of JE (EoEM)

along the entire length of the smooth muscle portion of the esophagus. Conversely, type I (classic) achalasia with no post-deglutitive contractility is likely the consequence of nearly complete aganglionosis. Type II achalasia falls between these extreme patterns [39].

Because classic achalasia (not subtyped as type I in old reports) has a loss of the Auerbach plexus and lymphocytedominant inflammation, many studies using animal models and patient samples were performed to investigate the unknown etiology. Viral infection, autoimmune

mechanism, and genetic factors were found to be related to achalasia; however, a definitive factor has not been discovered (Fig. 4) [40-46].

\section{Pathophysiology-based treatment of achalasia}

Curative therapies are currently not available for achalasia. However, fortunately, satisfactory long-term outcomes with pneumatic dilation (PD) or laparoscopic Heller myotomy (LHM), and, to a lesser extent, botulinum toxin 


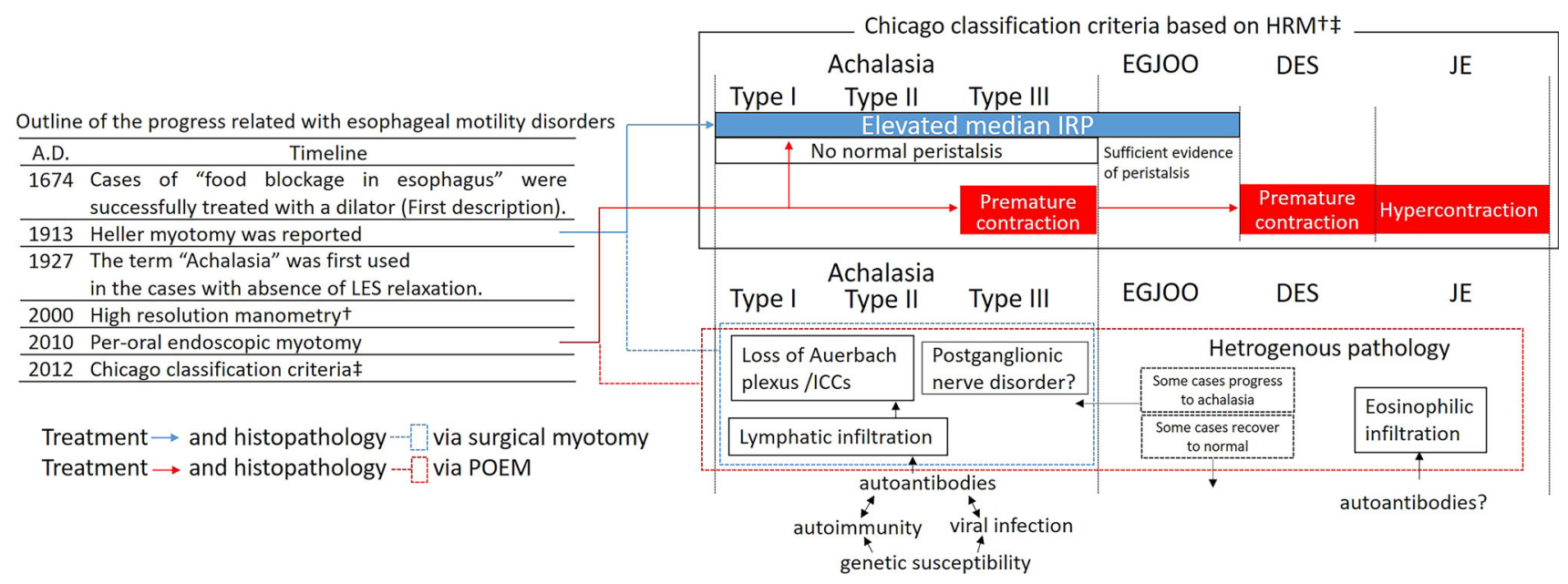

Fig. 4 (Left) Outline of the progress related with esophageal motility disorders including achalasia. (Upper right) the development of highresolution manometry and Chicago classification criteria categorizes in a clear manner a variety of esophageal motility disorders (Type IIII achalasia, EGJOO, DES, JE, and so on). Surgical myotomy has been performed to release the tight lower esophageal sphincter in achalasia (blue arrow [solid line]); peroral endoscopic myotomy
(POEM) also shows promise for totally mitigating abnormal premature- and hyper- contractions of type III achalasia, DES, and JE (red arrow [solid line]). (Lower right) histopathological examination via surgery (blue dotted line) as well as POEM (red dotted line) are expected to assist in elucidating the etiology of these various esophageal motility disorders
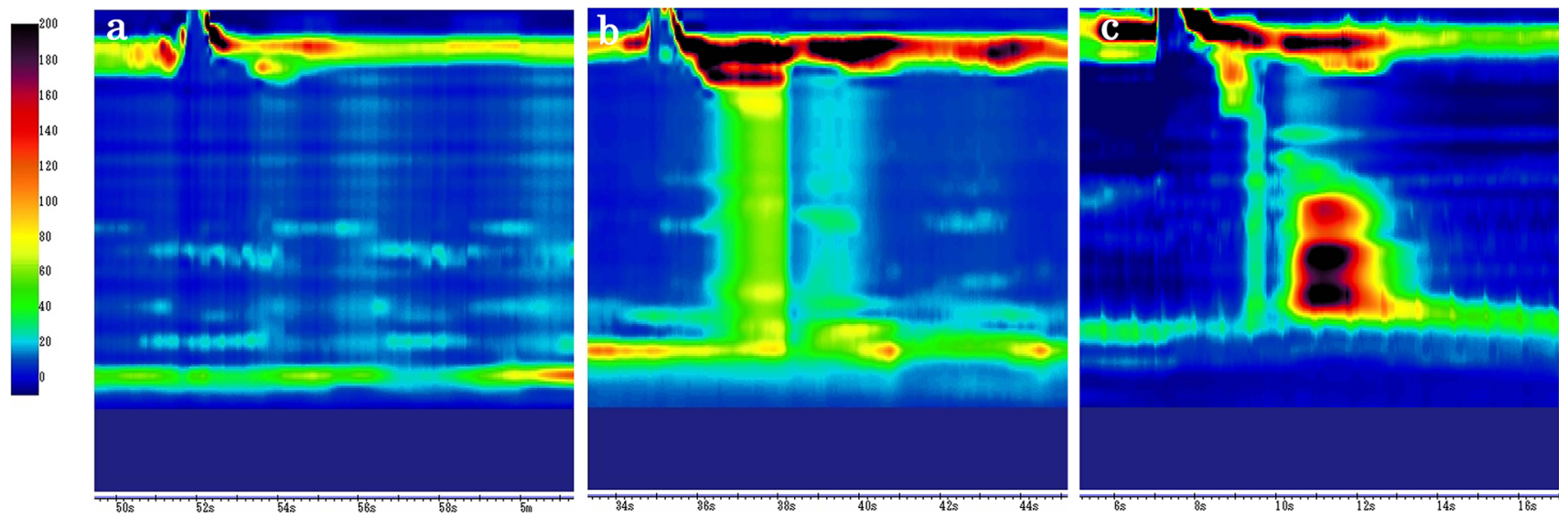

Fig. 5 a Type I achalasia; mean integrated relaxation pressure (IRP) $>$ upper limit of normal, $100 \%$ failed peristalsis (Classic achalasia). b Type II achalasia; Achalasia with esophageal compression: mean IRP $>$ upper limit of normal, no normal peristalsis,

injection have been reported for the esophagus-localized benign disorder [47, 48]. Although it varies by study design, a multicenter randomized controlled trial in Europe showed an 84 and $82 \%$ success rate after 5 years for LHM and PD, respectively [49]. The defining characteristic in the pathophysiology of achalasia is a loss of LES relaxation, and the release from LES pressurization is considered vitally important for a satisfactory outcome.

Recently, outcomes of achalasia treatment based on the manometric subtypes were reported. In a recent European trial using either PD or LHM for treatment of achalasia, success rates were significantly higher among patients with type II achalasia (96\%) than type I achalasia (81\%; panesophageal pressurization with $\geq 20 \%$ of swallows. c Type III achalasia; mean IRP $>$ upper limit of normal, no normal peristalsis, preserved fragments of distal peristalsis or premature (spastic) contractions with $\geq 20 \%$ of swallows

$P<0.01)$ or type III achalasia $(66 \% ; P<0.001)$. All patients with type III who were enrolled had persistent esophageal spasm during the follow-up period (although LES pressure was reduced), which is considered one reason for poor outcomes in type III [50]. The same conclusion for type III was driven by a meta-analysis of the correlation between treatment options and achalasia subtypes, where poor outcomes were also seen [51]. PD is effective only for tight LES, but not for abnormal contraction in the esophageal body. Furthermore, LHM may have been incompletely performed on the esophageal side due to limited surgical access from the gastric side. In contrast, a unique advantage of POEM over surgical LHM is that the length 
of the myotomy from the esophageal to gastric side can be adjusted freely based on the individual, because POEM is a peroral transluminal procedure [52]. Based on this, type III achalasia is expected to respond best to POEM. Khashab et al. reported a $93 \%$ clinical positive response for POEM to spastic disorders including type III achalasia in a $>6$ month follow-up period [53]. Further study with random allocation or with a long-term follow-up period is required to determine the advantages of POEM. A meta-analysis showed the rates of symptomatic GERD and esophagitis on gastroscopy were 8.5 and $13 \%$, respectively, after a shortterm follow-up after POEM [54].

\section{EGJOO, DES, and JE}

\section{Manometric definition of EGJOO and the spastic disorders, DES and JE}

Esophago-gastric junction outflow obstruction (EGJOO) is defined as an elevated IRP, with sufficient evidence of peristalsis such that the criteria for types I-III achalasia are not met. Several studies suggest a potential etiology of EGJOO to include an early form of achalasia, or a spontaneous recovery form with a return to normal; therefore, heterogeneous groups could be included in this pathological category (Fig. 6a) [55, 56].

Distal esophageal spasm (DES) is the most well-known esophageal spastic disorder. Although the term 'diffuse esophageal spasm' was obscurely used before, subsequent studies indicated that simultaneous contractions primarily in the distal esophagus, not in the proximal esophagus, occurred, and the term 'DES' and manometric definition of
DES were established as a normal median IRP, with $\geq 20 \%$ premature contractions ( $\mathrm{DL}<4.5 \mathrm{~s}$ ) (Fig. $6 \mathrm{~b}$ ) [57, 58].

The definition of a hyper-contractile esophagus (Jackhammer esophagus [JE]) is based on $\geq 20 \%$ of swallows with a DCI $>8000 \mathrm{mmHg} \mathrm{s} \mathrm{cm} \mathrm{with} \mathrm{normal} \mathrm{DL} \mathrm{(Fig.} \mathrm{7a)}$ [59]. Nutcracker esophagus (NE), with a mean DCI $>5,000 \mathrm{mmHg} \mathrm{s} \mathrm{cm} \mathrm{without} \mathrm{meeting} \mathrm{the} \mathrm{criteria} \mathrm{for}$ $\mathrm{JE}$, was once defined by the CC but removed in version 3.0 because the clinical significance of the hypertensive peristaltic contractions was questioned. It has been reported that EGJOO, DES and JE might progress to achalasia $[60,61]$.

\section{Histopathology of these esophageal motility disorders}

Few studies have been performed investigating the histopathology of EGJOO, DES, and JE because the manometric criteria were very recently clarified by the CC $[37,62]$, and the pool of individuals with these disorders is small.

We firstly reported a heterogeneous histology of NE/JE with or without eosinophil infiltration in the esophageal muscle layer; one with eosinophil infiltration was named eosinophilic esophageal myositis (EoEM) (Fig. 3f) [63-65]. Another esophageal eosinophilic disease, eosinophilic esophagitis (EoE), is known as a Th2-mediated allergy disorder. In EoE, eosinophils infiltrate the esophageal epithelium, and non-specific esophageal motility dysfunction is observed on HRM [66-69]. Our cases of NE/JE, otherwise known as 'EoEM', had eosinophil infiltration localized in the esophageal muscle layer, but did not
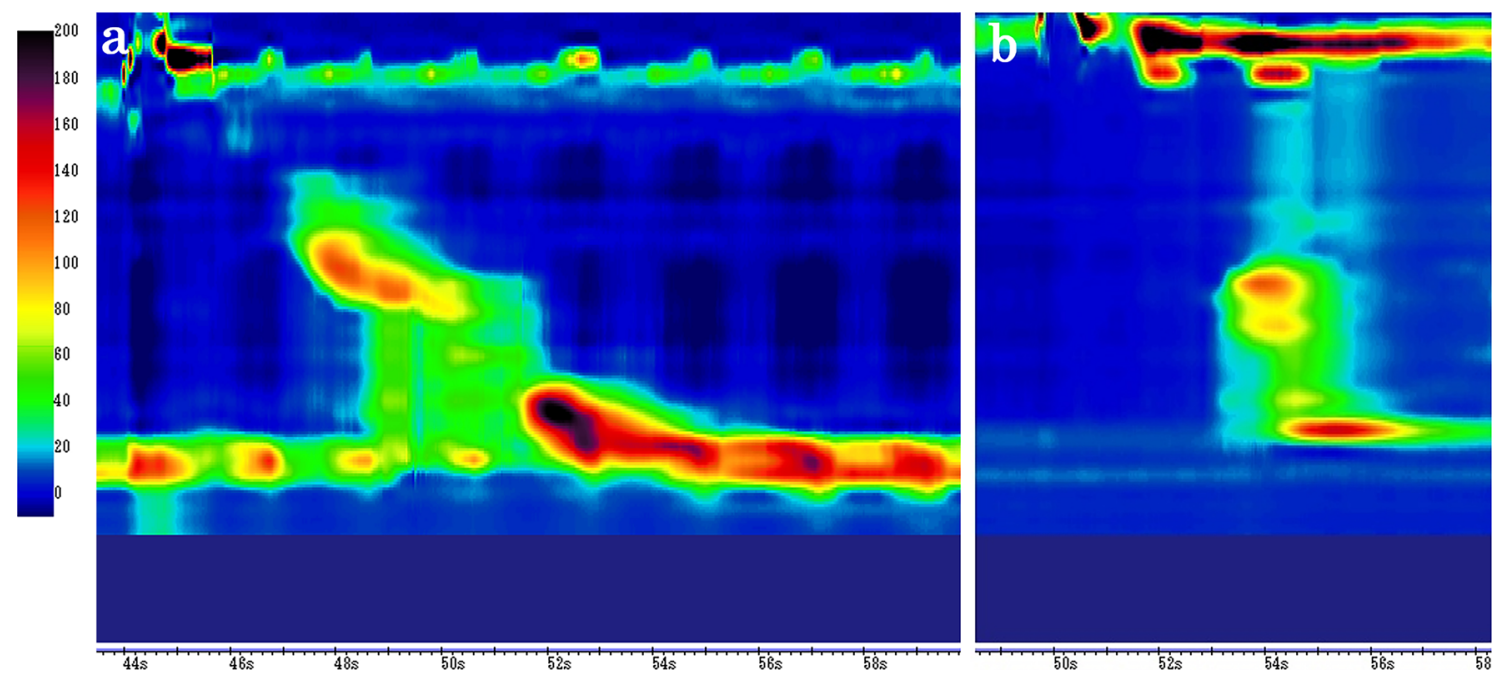

Fig. 6 a Esophago-gastric junction outflow obstruction; mean integrated relaxation pressure (IRP) $>$ upper limit of normal, some instances of intact peristalsis or weak peristalsis with small breaks

such that the criteria for achalasia are not fit. b Distal esophageal spasm; normal mean IRP, $\geq 20 \%$ premature contractions 

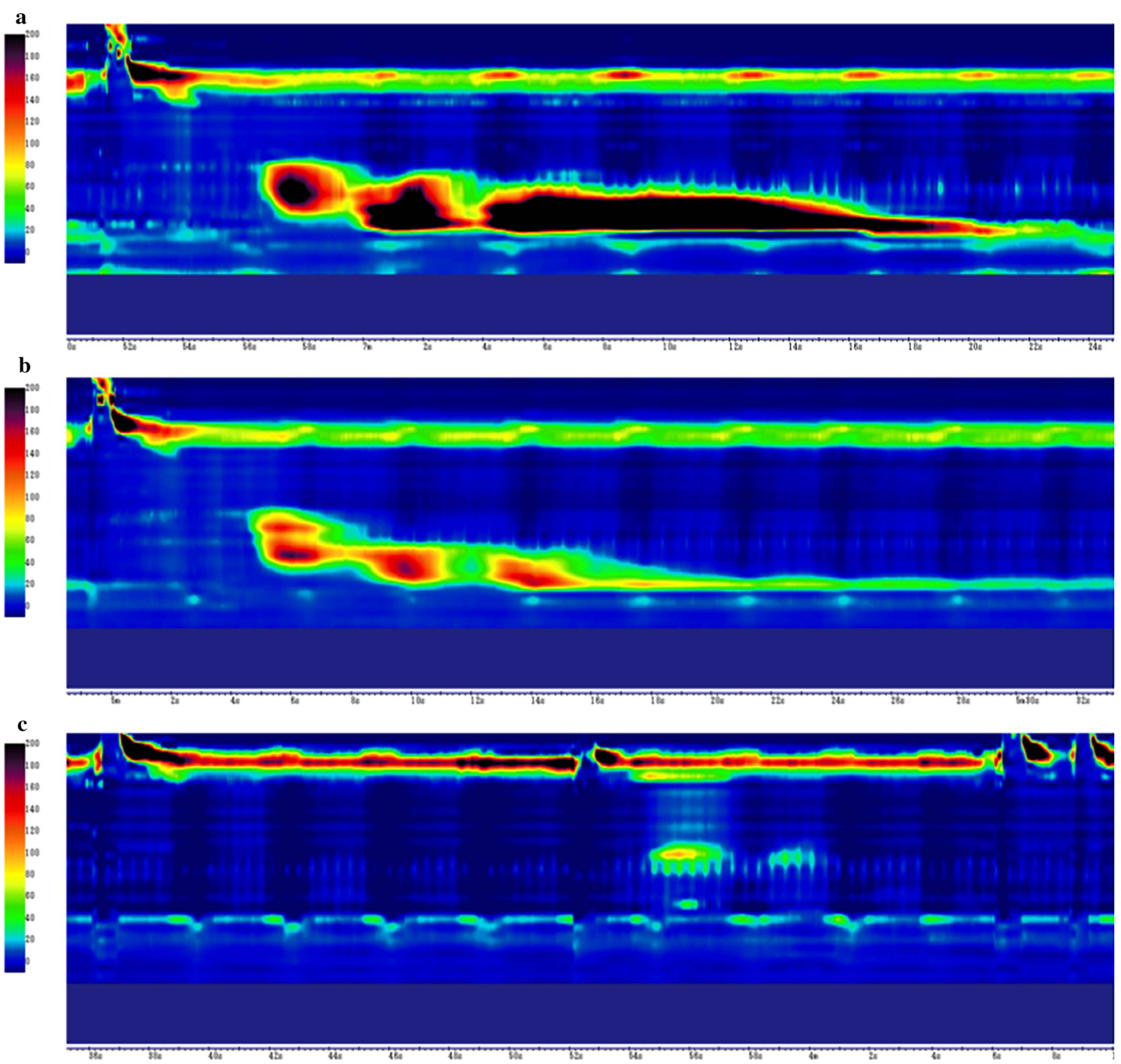

Fig. 7 a Jackhammer esophagus; at least two swallows distal contractile integral $(\mathrm{DCI})>8000 \mathrm{mmHg} \mathrm{s} \mathrm{cm} \mathrm{with} \mathrm{single} \mathrm{peaked}$ or multipeaked contraction. (maximum DCI; $30378.8 \mathrm{mmHg} \mathrm{s} \mathrm{cm}$, average DCI; $12566.5 \mathrm{mmHg} \mathrm{s} \mathrm{cm).} \mathrm{b} \mathrm{The} \mathrm{patient} \mathrm{was} \mathrm{diagnosed}$ with eosinophilic esophageal myositis via endoscopic ultrasoundguided fine needle aspiration; thereafter, oral prednisolone $(0.5 \mathrm{mg} /$ [kg day]) was initiated. His symptom was alleviated with lowering

involve the esophageal epithelium; moreover, immunostaining and gene expression analysis showed a considerably different pathology between EoEM and EoE [70, 71]. Funaki et al. reported a case of DES (diagnosed using 8-channel conventional manometry with infused catheter system), suspected as allergy-induced, responded to systemic steroid therapy [72]. This intriguing case showed no eosinophil infiltration in the esophageal epithelium on the vigor of esophageal contraction. (maximum DCI; $6726.9 \mathrm{mmHg} \mathrm{s} \mathrm{cm}$, average DCI; $3646.9 \mathrm{mmHg} \mathrm{s} \mathrm{cm}$ ). c Peroral endoscopic myotomy was successfully performed, and he became symptom free with prednisolone withdrawal. High-resolution manometry showed a total relief of esophageal abnormal contraction $(\mathbf{a}-\mathbf{c}$, same patient)

random biopsy; therefore, it was not diagnosed as EoE, but possibly EoEM. A case of a patient diagnosed with EoEM using endoscopic ultrasound-guided fine needle aspiration (EUS-FNA) was also reported [73], and systemic steroid alleviated his symptoms and reduced the intensity of esophageal contractions (Fig. 7b). Although the pathogenesis of esophageal spastic motility disorders is considered heterogeneous and includes non-eosinophil-related cases, 
some of these cases may be related to eosinophil infiltration in the histopathology (Fig. 4). In the lower part of the intestine, eosinophilic myenteric ganglionitis, with systemic steroid responsive, was reported [74].

\section{Pathophysiology-based treatment of esophageal spastic disorders}

Pharmacological treatment such as nitrates and calcium channel blockers both reduce LES pressure and esophageal contraction amplitude, which is considered effective for achalasia as well as esophageal spastic disorders [68].

As type III achalasia (with spastic contraction) responds well to POEM, and POEM is expected to be a promising therapy for other esophageal spastic disorders such as DES and JE [53], because premature contraction and hypercontraction, respectively, are the cornerstones of the pathophysiology, which can be best targeted with POEM (Fig. 4). EGJOO, the pathophysiology which is a loss or incomplete relaxation of the LES, can be treated using PD, LHM, or POEM [75].

In EoEM, systemic steroid therapy alleviated esophageal symptoms by mitigating esophageal hypercontraction, although systemic adverse events may prevent its longterm use [65]. In our practice, the long-term outcome of POEM was acceptable for dysphagia with complete resolution of esophageal hypercontraction in five patients with EoEM (follow-up period, 1-3 years) (Fig. 7c). Two patients continued to have chest pain once every two to 3 months; however, the frequency, intensity, and duration were all substantially reduced compared to that before POEM.

\section{Conclusion}

A variety of esophageal functional disorders are now categorized using the CC. HRM has become a gold standard for diagnosis and clinical decision making. Moreover, POEM has enabled a minimally invasive effective treatment for more esophageal motility disorders, and duringPOEM biopsy may become a major practice in histopathology, and is expected to provide new insights. At present, POEM appears to be an effective treatment for achalasia, EGJOO, DES, and JE. However, it may cause irreversible fibrotic change in the esophageal muscle layer, particularly in the LES [76], and could induce post-POEM gastroesophageal reflux disease [77, 78]. Further study is needed to elucidate the pathology and etiology of these complicated esophageal motility disorders, and allow for the development of a curative treatment.
Acknowledgements This work was supported by "JSPS Grants-inAid for Scientific Research: Grant number 16K19332".

\section{Compliance with ethical standards}

Conflict of interest The authors declare that they have no conflict of interest.

\section{References}

1. Willis T. Pharmaceutice rationalis: Sive diatribe de medicamentorum; operationibus in humano corpore. London: Hague-Comitis; 1674 . p. $18-9$

2. Hurst AF. Treatment of achalasia of the cardia (so-called "cardiospasm"). Lancet. 1927;1:618.

3. Vaezi MF, Pandolfino JE, Vela MF. ACG clinical Guideline: diagnosis and management of Achalasia. Am J Gastroenterol. 2013;108(8):1238-49.

4. Iwakiri K, Hoshihara Y, Kawami N, et al. The appearance of rosette-like esophageal folds ("esophageal rosette") in the lower esophagus after a deep inspiration is a characteristic endoscopic finding of primary achalasia. J Gastroenterol. 2010;45(4):422-5.

5. Minami $\mathrm{H}$, Isomoto $\mathrm{H}$, Miuma $\mathrm{S}$, et al. New endoscopic indicator of esophageal achalasia: "pinstripe pattern". PLoS One. 2015;10(2):e0101833.

6. Furuzawa-Carballeda J, Torres-Landa S, Valdovinos MA, et al. New insights into the pathophysiology of achalasia and implications for future treatment. World $\mathbf{J}$ Gastroenterol. 2016;22(35):7892-907.

7. Ghoshal UC, Daschakraborty SB, Singh R. Pathogenesis of achalasia cardia. World J Gastroenterol. 2012;18(24):3050-7.

8. Richter JE. Oesophageal motility disorders. Lancet. 2001;358(9284):823-8.

9. O'Neill OM, Johnston BT, Coleman HG. Achalasia: a review of clinical diagnosis, epidemiology, treatment and outcomes. World J Gastroenterol. 2013;19(35):5806-12.

10. Francis DL, Katzka DA. Achalasia: update on the disease and its treatment. Gastroenterology. 2010;139(2):369-74.

11. Dent J. A new technique for continuous sphincter pressure measurement. Gastroenterology. 1976;71:263-9.

12. Kahrilas P, Dodds W, Dent J, et al. Upper esophageal sphincter function during belching. Gastroenterology. 1986;91:133-40.

13. Kawai T, Yamagishi T. Comparison of investigation modalities for evaluation of esophageal peristaltic function. J Clin Biochem Nutr. 2008;42(3):185-90.

14. Clouse RE, Prakash C. Topographic esophageal manometry: an emerging clinical and investigative approach. Dig Dis. 2000;18(2):64-74.

15. Clouse RE, Staiano A, Alrakawi A, et al. Application of topographical methods to clinical esophageal manometry. Am J Gastroenterol. 2000;95(10):2720-30.

16. Gyawali CP. High resolution manometry: the Ray Clouse legacy. Neurogastroenterol Motil. 2012;24(Suppl 1):2-4.

17. Bredenoord AJ, Hebbard GS. Technical aspects of clinical highresolution manometry studies. Neurogastroenterol Motil. 2012;24(Suppl 1):5-10.

18. Pandolfino JE, Ghosh SK, Rice J, et al. Classifying esophageal motility by pressure topography characteristics: a study of 400 patients and 75 controls. Am J Gastroenterol. 2008;103(1):27-37.

19. Fox MR, Bredenoord AJ. Oesophageal high-resolution manometry: moving from research into clinical practice. Gut. 2008;57(3):405-23. 
20. Hädrich M, Tutuian R. Clinical impact of high-resolution manometry and impedance-pH monitoring. In: Bonavina L. editor. Innovation in Esophageal Surgery. Milano:Springer; 2012. pp. 5-16.

21. Bredenoord AJ, Fox M, Kahrilas PJ, et al. Chicago classification criteria of esophageal motility disorders defined in high resolution esophageal pressure topography. Neurogastroenterol Motil. 2012;24(Suppl 1):57-65.

22. Kahrilas PJ, Bredenoord AJ, Fox M, et al. The Chicago classification of esophageal motility disorders, v3.0. Neurogastroenterol Motil. 2015;27(2):160-74.

23. Pasricha PJ, Hawari R, Ahmed I, et al. Submucosal endoscopic esophageal myotomy: a novel experimental approach for the treatment of achalasia. Endoscopy. 2007;39(9):761-4.

24. Inoue $\mathrm{H}$, Minami $\mathrm{H}$, Kobayashi $\mathrm{Y}$, et al. Peroral endoscopic myotomy (POEM) for esophageal achalasia. Endoscopy. 2010;42(4):265-71.

25. Sato $H$, Inoue $H$, Ikeda $H$, et al. In vivo histopathological assessment of the muscularis propria in achalasia by using endocytoscopy (with video). Endosc Int Open. 2014;2(3):E178-82.

26. Kuribayashi S, Iwakiri K, Kawada A, et al. Variant parameter values-as defined by the Chicago criteria-produced by ManoScan and a new system with unisensor catheter. Neurogastroenterol Motil. 2015;27(2):188-94.

27. Xiao Y, Read A, Nicodeme F, et al. The effect of a sitting vs supine posture on normative esophageal pressure topography metrics and Chicago classification diagnosis of esophageal motility disorders. Neurogastroenterol Motil. 2012;24(10):e509-16.

28. Heller E. Extra mucous cardioplasty in chronic cardiospasm with dilatation of the esophagus (Extramukose Cardiaplastik mit dilatation des oesophagus). Mitt Grenzgels Med Chir. 1913;27:141-8.

29. Gockel I, Bohl JR, Eckardt VF, et al. Reduction of interstitial cells of Cajal (ICC) associated with neuronal nitric oxide synthase (n-NOS) in patients with achalasia. Am J Gastroenterol. 2008;103(4):856-64.

30. Gockel I, Bohl JR, Doostkam S, et al. Spectrum of histopathologic findings in patients with achalasia reflects different etiologies. J Gastroenterol Hepatol. 2006;21(4):727-33.

31. Hoshino M, Omura N, Yano F, et al. Immunohistochemical study of the muscularis externa of the esophagus in achalasia patients. Dis Esophagus. 2013;26(1):14-21.

32. Zarate N, Wang XY, Tougas $\mathrm{G}$, et al. Intramuscular interstitial cells of Cajal associated with mast cells survive nitrergic nerves in achalasia. Neurogastroenterol Motil. 2006;18(7):556-68.

33. Csendes A, Smok G, Braghetto I, et al. Histological studies of Auerbach's plexuses of the oesophagus, stomach, jejunum, and colon in patients with achalasia of the oesophagus: correlation with gastric acid secretion, presence of parietal cells and gastric emptying of solids. Gut. 1992;33(2):150-4.

34. Goldblum JR, Whyte RI, Orringer MB, et al. Achalasia. A morphologic study of 42 resected specimens. Am J Surg Pathol. 1994;18(4):327-37.

35. Kilic A, Krasinskas AM, Owens SR, et al. Variations in inflammation and nerve fiber loss reflect different subsets of achalasia patients. J Surg Res. 2007;143(1):177-82.

36. Clark SB, Rice TW, Tubbs RR, et al. The nature of the myenteric infiltrate in achalasia: an immunohistochemical analysis. Am J Surg Pathol. 2000;24(8):1153-8.

37. Sodikoff JB, Lo AA, Shetuni BB, et al. Histopathologic patterns among achalasia subtypes. Neurogastroenterol Motil. 2016;28(1):139-45.

38. Nakajima N, Sato H, Takahashi $K$, et al. Muscle layer histopathology and manometry pattern of primary esophageal motility disorders including achalasia. Neurogastroenterol Motil. 2017. https://doi.org/10.1111/nmo.12968

39. Kahrilas PJ, Boeckxstaens G. The spectrum of achalasia: lessons from studies of pathophysiology and high-resolution manometry. Gastroenterology. 2013;145(5):954-65.

40. des Varannes BS, Chevalier J, Pimont S, et al. Serum from achalasia patients alters neurochemical coding in the myenteric plexus and nitric oxide mediated motor response in normal human fundus. Gut. 2006;55(3):319-26.

41. Ruiz-de-Leon A, Mendoza J, Sevilla-Mantilla C, et al. Myenteric antiplexus antibodies and class II HLA in achalasia. Dig Dis Sci. 2002;47(1):15-9.

42. Palmieri O, Mazza T, Merla A, et al. Gene expression of muscular and neuronal pathways is cooperatively dysregulated in patients with idiopathic achalasia. Sci Rep. 2016;6:31549.

43. Furuzawa-Carballeda J, Aguilar-Leon D, Gamboa-Dominguez A, et al. Achalasia-an autoimmune inflammatory disease: a CrossSectional Study. J Immunol Res. 2015;2015:729217.

44. Gockel HR, Schumacher J, Gockel I, et al. Achalasia: will genetic studies provide insights? Hum Genet. 2010;128(4):353-64.

45. Kashyap P, Farrugia G. Enteric autoantibodies and gut motility disorders. Gastroenterol Clin N Am. 2009;37(2):397-410.

46. Gockel I, Becker J, Wouters MM, et al. Common variants in the HLA-DQ region confer susceptibility to idiopathic achalasia. Nat Genet. 2014;46(8):901-4.

47. Boeckxstaens GE, Annese V, des Varannes SB, et al. Pneumatic dilation versus laparoscopic Heller's myotomy for idiopathic achalasia. N Engl J Med. 2011;364(19):1807-16.

48. Zaninotto G, Annese V, Costantini M, et al. Randomized controlled trial of botulinum toxin versus laparoscopic heller myotomy for esophageal achalasia. Ann Surg. 2004;239(3):364-70.

49. Moonen A, Annese V, Belmans A, et al. Long-term results of the European achalasia trial: a multicentre randomised controlled trial comparing pneumatic dilation versus laparoscopic Heller myotomy. Gut. 2016;65(5):732-9.

50. Rohof WO, Salvador R, Annese V, et al. Outcomes of treatment for achalasia depend on manometric subtype. Gastroenterology. 2013;144(4):718-25 (quiz e13-4).

51. Ou YH, Nie XM, Li LF, et al. High-resolution manometric subtypes as a predictive factor for the treatment of achalasia: a meta-analysis and systematic review. J Dig Dis. 2016;17(4):222-35.

52. Inoue $\mathrm{H}$, Sato $\mathrm{H}$, Ikeda $\mathrm{H}$, et al. Per-oral endoscopic myotomy: a series of 500 patients. J Am Coll Surg. 2015;221(2):256-64.

53. Khashab MA, Messallam AA, Onimaru M, et al. International multicenter experience with peroral endoscopic myotomy for the treatment of spastic esophageal disorders refractory to medical therapy (with video). Gastrointest Endosc. 2015;81(5):1170-7.

54. Akintoye E, Kumar N, Obaitan I, et al. Peroral endoscopic myotomy: a meta-analysis. Endoscopy. 2016;48(12):1059-68.

55. van Hoeij FB, Smout AJ, Bredenoord AJ. Characterization of idiopathic esophagogastric junction outflow obstruction. Neurogastroenterol Motil. 2015;27(9):1310-6.

56. Perez-Fernandez MT, Santander C, Marinero A, et al. Characterization and follow-up of esophagogastric junction outflow obstruction detected by high resolution manometry. Neurogastroenterol Motil. 2016;28(1):116-26.

57. Sperandio M, Tutuian R, Gideon RM, et al. Diffuse esophageal spasm: not diffuse but distal esophageal spasm (DES). Dig Dis Sci. 2003;48(7):1380-4.

58. Pandolfino JE, Roman S, Carlson D, et al. Distal esophageal spasm in high-resolution esophageal pressure topography: defining clinical phenotypes. Gastroenterology. 2011;141(2):469-75.

59. Roman S, Pandolfino JE, Chen J, et al. Phenotypes and clinical context of hypercontractility in high-resolution esophageal pressure topography (EPT). Am J Gastroenterol. 2012;107(1):37-45. 
60. Roman S, Kahrilas PJ. Distal esophageal spasm. Curr Opin Gastroenterol. 2015;31(4):328-33.

61. Huang L, Pimentel M, Rezaie A. Do Jackhammer contractions lead to achalasia? A longitudinal study. Neurogastroenterol Motil. 2017. https://doi.org/10.1111/nmo.12953

62. Takahashi K, Sato H, Sato Y, et al. Education and Imaging. Gastroenterology: histopathological investigation of distal esophageal spasm (DES) using per-oral endoscopic myotomy (POEM). J Gastroenterol Hepatol. 2015;30(7):1113.

63. Sato H, Takeuchi M, Takahashi K. Eosinophilic infiltration of the muscularis propria in a patient with jackhammer esophagus treated with per-oral endoscopic myotomy. Clin Gastroenterol Hepatol. 2015;13(4):e33-4.

64. Takahashi K, Sato H, Sato Y. An unusual case of an esophageal functional disorder. Gastroenterology. 2015;149(6):e15-6.

65. Sato H, Takeuchi M, Takahashi K, et al. Nutcracker and jackhammer esophagus treatment: a three-case survey, including two novel cases of eosinophilic infiltration into the muscularis propria. Endoscopy. 2015;47(9):855-7.

66. Martin Martin L, Santander C, Lopez Martin MC, et al. Esophageal motor abnormalities in eosinophilic esophagitis identified by high-resolution manometry. J Gastroenterol Hepatol. 2011;26(9):1447-50.

67. Roman S, Hirano I, Kwiatek MA, et al. Manometric features of eosinophilic esophagitis in esophageal pressure topography. Neurogastroenterol Motil. 2011;23(3):208-14 (e111).

68. Roman S, Kahrilas PJ. Management of spastic disorders of the esophagus. Gastroenterol Clin N Am. 2013;42(1):27-43.

69. Savarino EV, Tolone S, Bartolo O, et al. The GerdQ questionnaire and high resolution manometry support the hypothesis that proton pump inhibitor-responsive oesophageal eosinophilia is a
GERD-related phenomenon. Aliment Pharmacol Ther. 2016;44(5):522-30.

70. Sato H, Nakajima N, Hasegawa G, et al. Immunohistochemical differentiation of eosinophilic esophageal myositis from eosinophilic esophagitis. J Gastroenterol Hepatol. 2017;32(1):106-13.

71. Sato H, Nakajima N, Takahashi K, et al. Proposed criteria to differentiate heterogeneous eosinophilic gastrointestinal disorders of the esophagus, including eosinophilic esophageal myositis. World J Gastroenterol. 2017;23(13):2414-23.

72. Funaki Y, Iida A, Shimozato A, et al. A case of diffuse esophageal spasm successfully treated by steroid therapy. Nihon Shokakibyo Gakkai Zasshi. 2014;111(9):1774-81.

73. Igarashi R, Irisawa A, Shibukawa G, et al. Eosinophilic esophageal myositis diagnosed by endoscopic ultrasound-guided fineneedle aspiration biopsy: a case report. Clin J Gastroenterol. 2016;9(5):285-8.

74. Schäppi MG, Smith VV, Milla PJ, et al. Eosinophilic myenteric ganglionitis is associated with functional intestinal obstruction. Gut. 2003;52:752-5.

75. Tuason J, Inoue H. Current status of achalasia management: a review on diagnosis and treatment. J Gastroenterol. 2017;52(4):401-6.

76. Sato H, Sagara S, Suzuki K, et al. Assessments of histologic changes after peroral endoscopic myotomy. Gastrointest Endosc. 2016;84(2):377-8.

77. Shiwaku H, Inoue H, Sasaki T, et al. A prospective analysis of GERD after POEM on anterior myotomy. Surg Endosc. 2016;30(6):2496-504.

78. Bhayani NH, Kurian AA, Dunst CM, et al. A comparative study on comprehensive, objective outcomes of laparoscopic Heller myotomy with per-oral endoscopic myotomy (POEM) for achalasia. Ann Surg. 2014;259(6):1098-103. 